\title{
Combination of Adsorption-Diffusion Model with Computational Fluid Dynamics for Simulation of a Tubular Membrane Made from SAPO-34 Thin Layer Supported by Stainless Steel for Separation of $\mathrm{CO}_{2}$ from $\mathrm{CH}_{4}$
}

\author{
Fatemeh Sadat Banitaba, Zahra Mansourpour and Shohreh Fatemi*
}

School of Chemical Engineering, College of Engineering, University of Tehran, Iran

\begin{abstract}
Modeling of $\mathrm{CO}_{2} / \mathrm{CH}_{4}$ separation using SAPO-34 tubular membrane was performed by computational fluid dynamics. The Maxwell-Stefan equations and Langmuir isotherms were used to describe the permeate flux through the membrane and the adsorption-diffusion, respectively. Three-dimensional Navier-Stokes momentum balances in feed and permeate side coupled with adsorption-diffusion equations from the membrane were simultaneously solved by ANSYS FLUENT software. The velocity and concentration profiles were determined in both feed and permeate sides. There was a good agreement between simulation and experimental results and root mean square deviation for $\mathrm{CH}_{4}$ and $\mathrm{CO}_{2}$ are 0.13 and $0.1\left(\mathrm{mmol} \mathrm{m}^{-2} \mathrm{~s}^{-1}\right)$, respectively. The concentration polarization effect was observed in the results. The effect of the process variables were investigated to find out the most influential parameters in permeation and purity. The impact of operating conditions on separation were studied and showed that for enhancement of separation efficiency of $\mathrm{CO}_{2}$ from $\mathrm{CH}_{4}$, feed pressure, feed flow rate and tube radius and number of membrane modules in series should be increased, whereas flow configuration has less significant effect.
\end{abstract}

Keywords: Computational fluid dynamic, tubular zeolite membrane, $\mathrm{CO}_{2} / \mathrm{CH}_{4}$ separation, SAPO-34, Adsorptiondiffusion mechanism.

\section{INTRODUCTION}

Methane as the major component of natural gas usually contains carbon dioxide impurity with a broad range of $2 \%$ up to $40 \%$ in different sources, which must be removed because it reduces the energy content of the gas and because of its acidic and corrosive effects. The pipeline specifications for natural gas require a $\mathrm{CO}_{2}$ concentration below 2-3\% [1]. For separation of $\mathrm{CO}_{2}$ from natural gas, several technologies, such as absorption, adsorption, cryogenic and membrane separation, have been investigated and used in recent years [2]. The advantages of membrane gas separation over traditional techniques include low-energy consumption, ease of operation, and low environmental impacts [3]. Polymeric membranes are commercially available for $\mathrm{CO}_{2}$ separation from natural gas, but the main problem that limits the use of these membranes, is their poor performance stability at high pressure and in the presence of highly soluble components. Because of good thermal, mechanical, and chemical stability, zeolite membranes potentially have advantages over polymeric membranes. SAPO-34 is one of the micropore zeolite like material with Chabazite natural zeolite structure that displays high $\mathrm{CO}_{2} / \mathrm{CH}_{4}$ selectivity

*Address correspondence to this author at the School of Chemical Engineering, College of Engineering, University of Tehran, Iran; Tel: + 9821 66967784; Fax: + 9821 66967784; E-mail: shfatemi@ut.ac.ir due to a combination of differences in diffusivity and competitive adsorption [4]. SAPO-34 crystals with 0.38 $\mathrm{nm}$ micropore diameter act as a molecular sieve for $\mathrm{CO}_{2}$ with $0.33 \mathrm{~nm}$ kinetic diameter. $\mathrm{CO}_{2}$ can adsorb and diffuse through the crystalline surface of SAPO-34 whereas methane with $0.38 \mathrm{~nm}$ diameter is hindered by the pore mouth of SAPO-34 to diffuse and adsorb through the crystalline micropores [5].

Computational techniques have the potential of improving the understanding of mass transfer in membrane separation systems. Computational fluid dynamics (CFD) is one of the numerical techniques used for simulating fluid flow and is a powerful tool in engineering systems. It could enable to understand the fluid flow in membrane separation processes, and help to optimize the design conditions.

CFD has been generally applied in membrane processes involving the separation of liquids [6,7]. Although researches on CFD modeling for gas separation membrane are limited, in the recent years with development of membrane material for gas separation, application of the CFD technique for gas separation modeling has been increased [8-16]. Koukou et al. [8] and Takaba and Nakao [9] reported that the simplified plug flow assumption on both sides of the ceramic membrane does not allow properly predicting the experimental data and does not show concentration polarization effects. Abdel-jawad et al. [10] used the phenomenological equations to describe 
the mass flux through the membrane. Kawachale et al. [11] have focused on the species distribution close to a polymeric membrane for VOC separations and described mass transfer through membrane by simple Fick equation. Coroneo et al. [12, 13] presented a three dimensional geometry to model $\mathrm{H}_{2}$ purification in the ceramic and metallic membranes modules using CFD. Recently, Ji et al. $[14,15]$ simulated a multi tube COxS membrane with CFD approach in one- [14] and twodimension(s) [15]. They used Maxwell-Stefan equation formulation to describe membrane mass transfer. Li et al. [16] simulated an axisymmetric BSCF $\left(\mathrm{Ba}_{0.5} \mathrm{Sr}_{0.5} \mathrm{Co}_{0.8} \mathrm{Fe}_{0.203-\delta}\right)$ membrane for $\mathrm{O}_{2} / \mathrm{N}_{2}$ separation with a two dimensional fluent simulation and investigated the concentration polarization of oxygen. They concluded that with increasing sweep flow rates, the effect of concentration polarization is less pronounced.

In this study, the CFD approach is coupled with the Maxwell-Stefan equations to reveal the local variation of carbon dioxide and methane concentration and gas velocity profile near the membrane surface as a result of $\mathrm{CO}_{2}$ and $\mathrm{CH}_{4}$ permeations. The predicted model results of $\mathrm{CO}_{2}$ and $\mathrm{CH}_{4}$ permeations are compared with the experimental results obtained from a tubular SAPO34 membrane in a lab scale. Moreover, effects of variations in operating variables include feed pressure, feed flow rate, flow configuration, membrane tube radius, and number of membranes in series are investigated.

\section{EXPERIMENTAL DATA}

The zeolite membrane was prepared as reported by Jabbari et al. [17]. Porous tubular stainless steel was used as a support with 9 and $10 \mathrm{~mm}$ internal and external diameter, respectively. The SAPO-34 film was grown on the inner surface of the support with the mean layer thickness of $4 \mu \mathrm{m}$. Membrane module consists of a cylindrical shell with a length of $70 \mathrm{~mm}$ and a diameter of $16.4 \mathrm{~mm}$, equipped with inlet and outlet pipes having a diameter of $3.2 \mathrm{~mm}$, and of an internal tube, containing the tubular zeolite membrane. A scheme of membrane module is shown in Figure 1. Feed enters the tube and permeate flow exits from the shell side. No sweep gas was used in the permeation tests, thus the inlet valve of the sweep gas was blocked during experiments. The permeate side was kept at atmospheric pressure, feed side pressure varied from 1-6 barg and experiments were carried out at room temperature of $25^{\circ} \mathrm{C}$. Equimolar mixture of $\mathrm{CO}_{2} / \mathrm{CH}_{4}$ was fed to the membrane module. The schematic diagram of the permeation test setup has been shown in Figure 2.

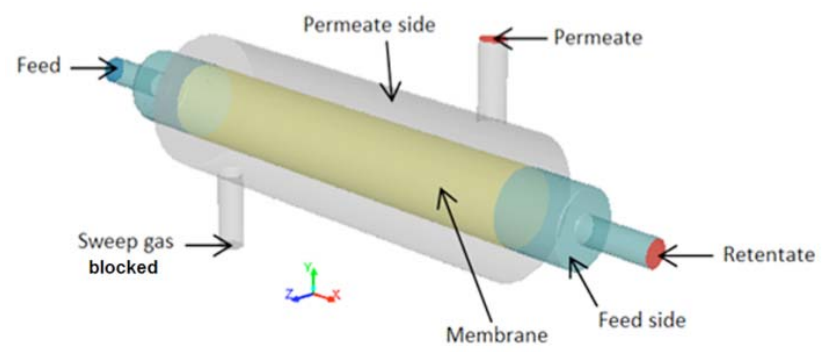

Figure 1: A scheme of membrane module.

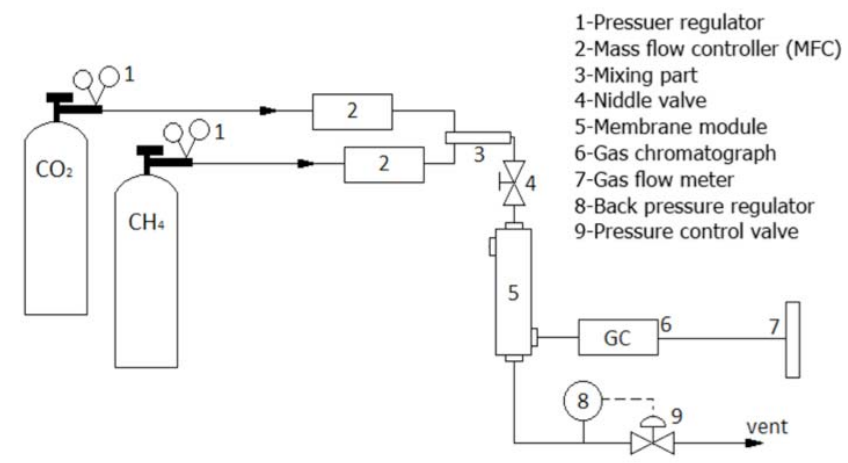

Figure 2: A schematic diagram of the permeation test setup.

\section{MODEL DEVELOPMENT}

\section{CFD Model}

In order to simulate the laminar flow of the gas mixture in the feed and permeate side of membrane module, the steady-state mass and momentum conservation equations over the three-dimensional domain were derived and solved. Also, a set of gas species conservation equations were solved to account for the separation. In addition, source terms were used to describe species transfer through the membrane film. The governing equations, based on the physical principles of continuity, momentum conservation and solutes conservation are shown in equations 1 to 3 .

Mass conservation equation (continuity):

$\nabla \cdot(\rho U)=S$

Momentum conservation equation (Navier-stokes):

$\nabla \cdot(\rho U U)=-\nabla P+\nabla \cdot \tau$

Species conservation equation:

$\nabla \cdot\left(\rho U Y_{i}\right)=-\nabla \cdot\left(\rho D \nabla Y_{i}\right)+S_{i}$ 
Where $\rho$ is the density, $U$ is the velocity vector, $\tau$ is the viscous stress tensor, $P$ is the pressure, $S$ and $S_{i}$ are source terms to account for the total mass flow and mass flow of species $i$ through membrane, respectively. It must be noted that all source terms in equations 1 to 3 are zero everywhere in solution domain, except at the interface with the membrane where the source matches with the total membrane flux.

\section{Source Term Formulation}

In this section, the theory of Maxwell-Stefan is developed for demonstration of diffusion through the zeolite membrane, which would be applied for prediction the source term in the model equations.

The species flux and total flux through the membrane were considered as follows:

$S_{i}=M_{i} \frac{A_{c}}{V_{c}} J_{i}$

$S=\sum S_{i}$

Where $A_{c}$ is the cell area, $V_{c}$ is the cell volume and $M_{i}$ is molecular mass i species. A mathematical model was developed to describe the mass transfer through zeolite film on the basis of the following assumptions: (i) the effect of support layer and defects of the zeolite film are neglected (ii) the transport of the absorbing components through the zeolite membrane occurs due to adsorption-diffusion, described by the MaxwellStefan model and (iii) gas translational diffusion is neglected due to the low temperature. Permeation flux of single component trough zeolite film with the singlesite Langmuir adsorption isotherm is [18]:

$J=q_{\text {sat }} \frac{\rho_{z} \boldsymbol{D}}{\delta} \ln \frac{1-\theta_{\text {perm }}}{1-\theta_{\text {feed }}}$

$\theta=\frac{q}{q_{\text {sat }}}=\frac{b P}{1+b P}$

Where $\boldsymbol{D}$ is Maxwell-Stefan diffusivity and $\theta$ is coverage fraction. the permeation flux through membrane for a mixture could be described with generalized Maxwell-Stefan formulation [19] as follows:

$J=\rho_{z}\left[q_{s a t}\right][B]^{-1}[\Gamma](\nabla \theta)$

Where $[B]$ is Maxwell-Stefan diffusivity matrix and $[\Gamma]$ is thermodynamic matrix. The values of these matrixes are obtained from:
$B_{i i}=\frac{1}{\boldsymbol{D}_{i}}+\sum_{\substack{j=1 \\ j \neq i}}^{n} \frac{\theta_{j}}{\boldsymbol{D}_{i j}}, B_{i j}=\frac{-\theta_{i}}{\boldsymbol{D}_{i j}}, \Gamma_{i j}=\frac{\theta_{i}}{P_{i}} \frac{\partial P_{i}}{\operatorname{Pi} \theta_{j}}$

To relate coverage fraction, $\theta_{i}$ to the partial pressure, two models could be used, including ideal adsorption solution theory (IAST) [20] and multicomponent Langmuir isotherm [21]. In this work, we used multicomponent Langmuir model for binary mixture, thus we have:

$\theta_{i}=\frac{q_{i}}{q_{i, s a t}}=\frac{b_{i} P_{i}}{1+\sum_{j=1}^{2} b_{j} P_{j}}$

For ease of numerical calculation, linear profile for coverage fractions were considered, thus the fluxes can be written as:

$$
\begin{aligned}
& J_{1}=q_{s a t, 1} \frac{\rho_{z} \boldsymbol{D}_{1}}{\delta} \frac{\left(1-\theta_{2}+\boldsymbol{D}_{2} / \boldsymbol{D}_{12} \theta_{1}\right) \Delta \theta_{1}+\left(\theta_{1}+\boldsymbol{D}_{2} / \boldsymbol{D}_{12} \theta_{1}\right) \Delta \theta_{2}}{\left(1+\boldsymbol{D}_{2} / \boldsymbol{D}_{12} \theta_{1}+\boldsymbol{D}_{1} / \boldsymbol{D}_{12} \theta_{2}\right)\left(1-\theta_{1}-\theta_{2}\right)} \\
& J_{2}=q_{s a t, 2} \frac{\rho_{z} \boldsymbol{D}_{2}}{\delta} \frac{\left(1-\theta_{1}+\boldsymbol{D}_{1} / \boldsymbol{D}_{12} \theta_{2}\right) \Delta \theta_{2}+\left(\theta_{2}+\boldsymbol{D}_{1} / \boldsymbol{D}_{12} \theta_{2}\right) \Delta \theta_{1}}{\left(1+\boldsymbol{D}_{2} / \boldsymbol{D}_{12} \theta_{1}+\boldsymbol{D}_{1} / \boldsymbol{D}_{12} \theta_{2}\right)\left(1-\theta_{1}-\theta_{2}\right)}
\end{aligned}
$$

\section{CFD SIMULATION DETAILS}

Model development and simulations were performed using ANSYS FLUENT ${ }^{\circledR} 13.0$ commercial CFD software and GAMBIT 2.2. The geometrical configuration of the simulated apparatus was as described in experimental data section. The computational domain consists of about 506000 hexahedral and tetrahedral elements. The membrane in the domain was defined as shadowed wall, while all other edges represent the barriers of the remaining cell geometry. Boundary conditions for feed, sweep gas permeate and retentate streams were obtained from empirical data as velocity inlet and pressure outlets, respectively and are listed in Table 1 . Viscous model was set to 'Laminar', and the discretization of the governing equations was performed using a segregated incompressible flow solver. The SemiImplicit Method for Pressure-Linked Equations

Table 1: Defined Boundary Condition for Geometry

\begin{tabular}{|c|c|c|}
\hline Stream name & Boundary condition & value \\
\hline \hline feed & velocity inlet & $\begin{array}{c}0.125 \mathrm{~m} / \mathrm{s} \\
\text { mole fraction }\end{array}$ \\
\hline sweep gas & velocity inlet & $0.5 \mathrm{~m} / \mathrm{s}$ \\
\hline permeate & pressure outlet & 0 bar gauge \\
\hline retentate & pressure outlet & $1-6$ bar gauge \\
\hline
\end{tabular}


(SIMPLE) formulation of pressure-velocity coupling was used to obtain the required corrections to the pressure and velocity fields. The convergence criteria for the continuity and velocity parameters were fixed to $10^{-5}$. Pressure was set to 'Linear' and momentum was set to 'Second Order Upwind' discretization schemes for more accurate results [22].

\section{User Defined Function (UDF)}

As mentioned above, equations 1 to 3 were solved to specify fluid dynamics and source terms in those equations describing transport of gas through the membrane. The source terms were achieved using a series of user defined functions (UDFs) in ANSYS FLUENT ${ }^{\circledR}$ software according to the formulation in the CFD model section. Figure 3 shows the flowchart of the numerical solution procedure. After initializations and boundary conditions setting, source terms were calculated from cells near to membrane walls in both feed and permeate sides by a DEFINE_ADJUST macro. These sources were added to continuity and species conservation equations by two DEFINE_SOURCE macros.

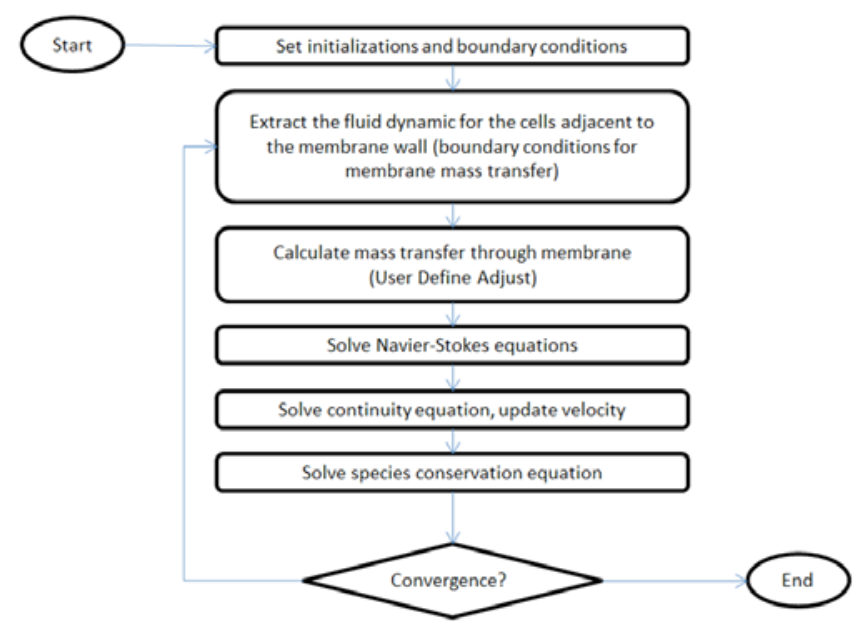

Figure 3: The flowchart of the numerical solution procedure.

\section{RESULTS AND DISCUSSION}

\section{Model Validation}

Figure 4 shows the experimental $\mathrm{CH}_{4}$ and $\mathrm{CO}_{2}$ fluxes from the permeate side, as a function of pressure drop across the membrane. The points are the experimental data. For both gases the fluxes continuously are increased with pressure difference. Other researchers have reported similar behaviors for these gases through SAPO-34 membranes when pressure drop is increased [23]. Figure 4 also shows the result obtained from simulation with continues lines.
As can be seen they have good agreement with experimental data. Root mean square deviation for $\mathrm{CH}_{4}$ and $\mathrm{CO}_{2}$ are 0.13 and $0.1\left(\mathrm{mmol} \mathrm{m}^{-2} \mathrm{~s}^{-1}\right)$, respectively. $\mathrm{CO}_{2}$ mole fraction at permeate for these cases are shown in Figure $\mathbf{5}$ and in which experimental and model results could be compared.

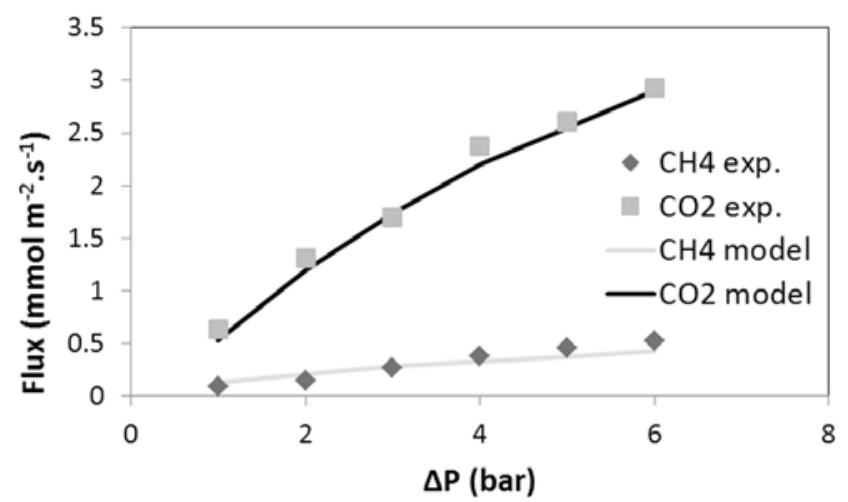

Figure 4: $\mathrm{CH}_{4}$ and $\mathrm{CO}_{2}$ fluxes from the permeate side, as a function of pressure drop across the membrane.

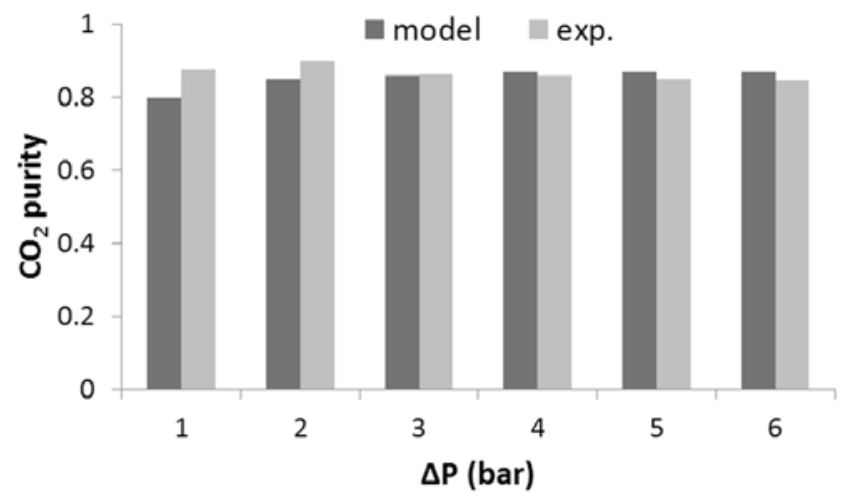

Figure 5: $\mathrm{CO}_{2}$ mole fraction at permeate as a function of pressure drop.

In addition, simulation results could be shown in graphical view with velocity and concentration maps on the arbitrary sections of geometry such as $z=0$ (see Figure $6 a$ ). Figure $\mathbf{6 b}$ shows velocity vector in this plane. Direction of vectors near the membrane wall clearly shows the direction of mass transfer through membrane. In addition, Figure $\mathbf{6 b}$ shows gas stream which enter from the feed inlet, exit from the retentate outlet and a portion of it diffuses through membrane and exit from the permeate outlet.

Figure 7a illustrates the $\mathrm{CO}_{2}$ mole fraction profile at feed side on the $\mathrm{z}=0$ plane. It can be seen from the mole fraction map that $\mathrm{CO}_{2}$ mole fraction has shown dispersion in both radial and axial directions. It is clear that $\mathrm{CO}_{2}$ molecules permeate from the membrane more than $\mathrm{CH}_{4}$ molecules do, therefore mole fraction of 


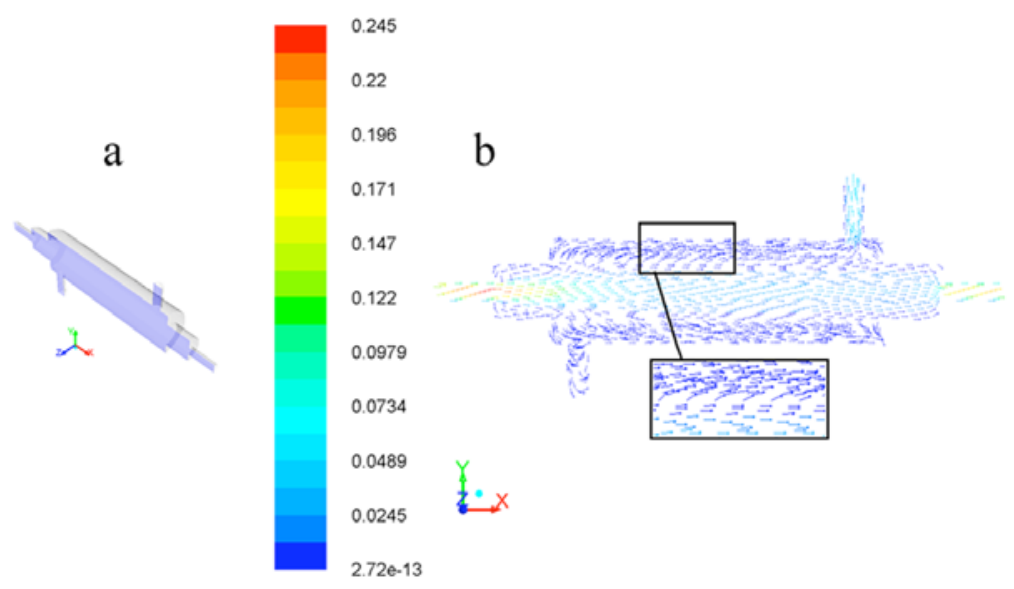

Figure 6: a) Velocity map on the sections of geometry $z=0, \mathbf{b})$ velocity vector in this plane.

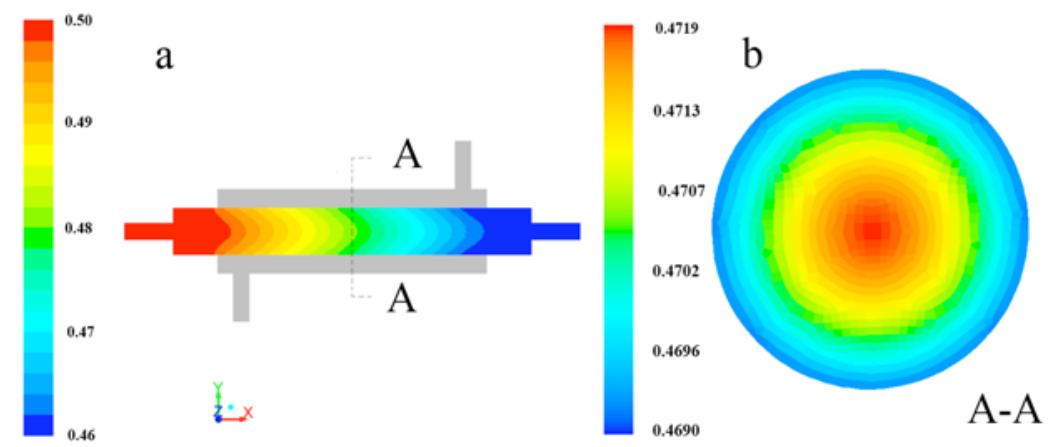

Figure 7: a) The $\mathrm{CO}_{2}$ mole fraction profile at feed side on the $\mathrm{z}=0$ plane, b) Radial profile of $\mathrm{CO}_{2}$ mole fraction.

$\mathrm{CO}_{2}$ is decreasing in the axial direction. Radial profile of $\mathrm{CO}_{2}$ mole fraction is also showed in Figure $7 \mathbf{b}$. As can be seen, $\mathrm{CO}_{2}$ mole fraction near the membrane wall is decreasing due to permeation through membrane and it shows concentration polarization effect at the feed side. However, the low flux through the membrane weakens this effect.

Figure 8 shows $\mathrm{CO}_{2}$ mole fraction profile at the permeate side. $\mathrm{CO}_{2}$ mole fraction decreases along the

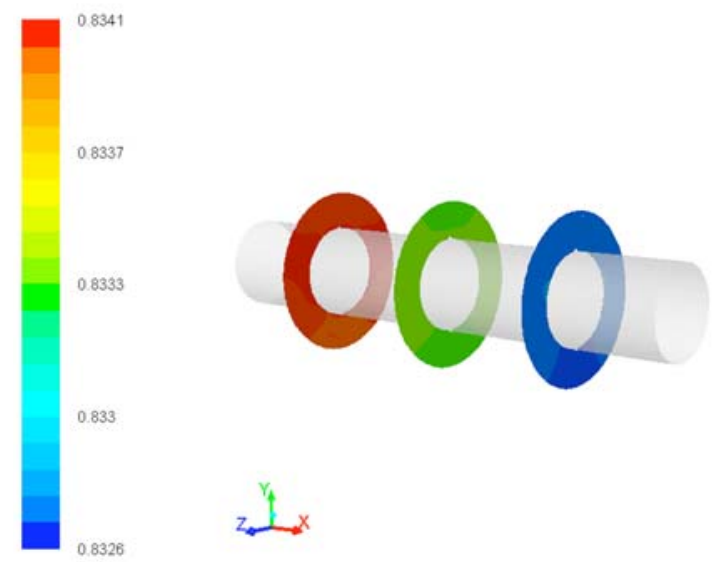

Figure 8: $\mathrm{CO}_{2}$ mole fraction profile at the permeate side. axis at permeate side. As $\mathrm{CO}_{2}$ molecules permeate from feed side to the permeate side, $\mathrm{CO}_{2}$ content is reduced in feed side, thus by decreasing driving force, $\mathrm{CO}_{2}$ content would be reduced in permeate side.

\section{Sensitivity Analysis}

For understanding the impact of variation of operational variables and module design parameters on $\mathrm{CO}_{2}$ permeation flow rate and mole fraction, some additional simulation should be performed. The changes in operating conditions were investigated as follows.

\section{Feed Pressure}

To estimate the effect of feed pressure on separation process, simulations were performed with two pressures of 4 and 8 barg in feed side while feed flow rate remain constant. Results are shown in Figure 9. In Figure $9 \mathrm{a}$, as it was expected, pressure has significant impact on $\mathrm{CO}_{2}$ permeate flow rate and increased with pressure difference because the pressure difference is considered as a driving force for permeation through the membrane. Figure $9 \mathrm{~b}$ shows a small effect on the $\mathrm{CO}_{2}$ mole fraction at the permeate 

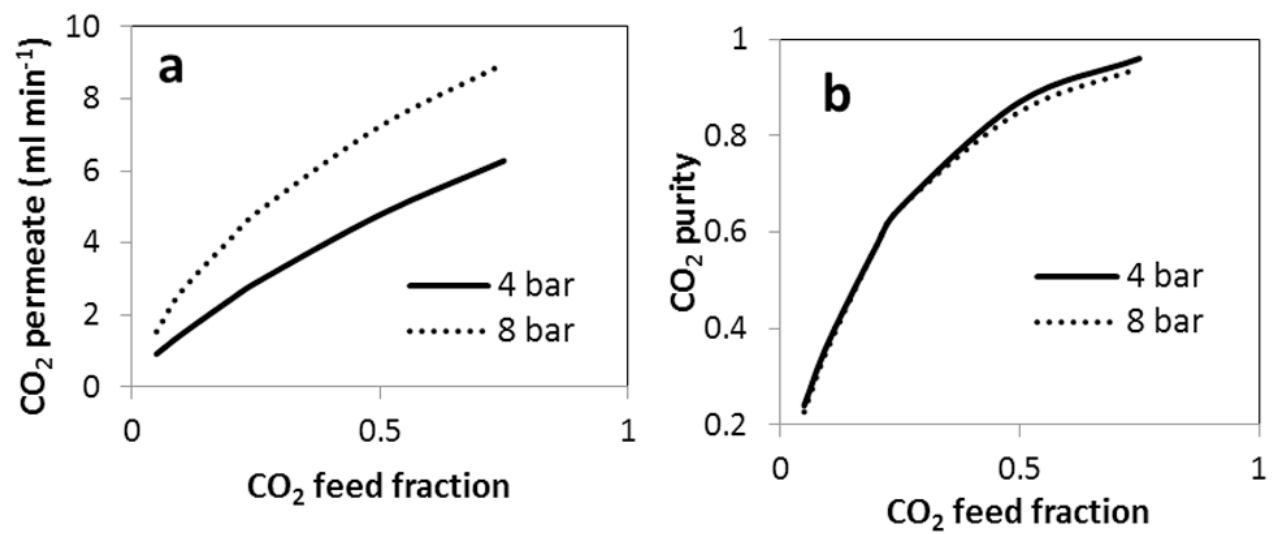

Figure 9: a) $\mathrm{CO}_{2}$ permeate flow rate at various pressure difference, b) $\mathrm{CO}_{2}$ mole fraction at the permeate Side at various pressure difference.
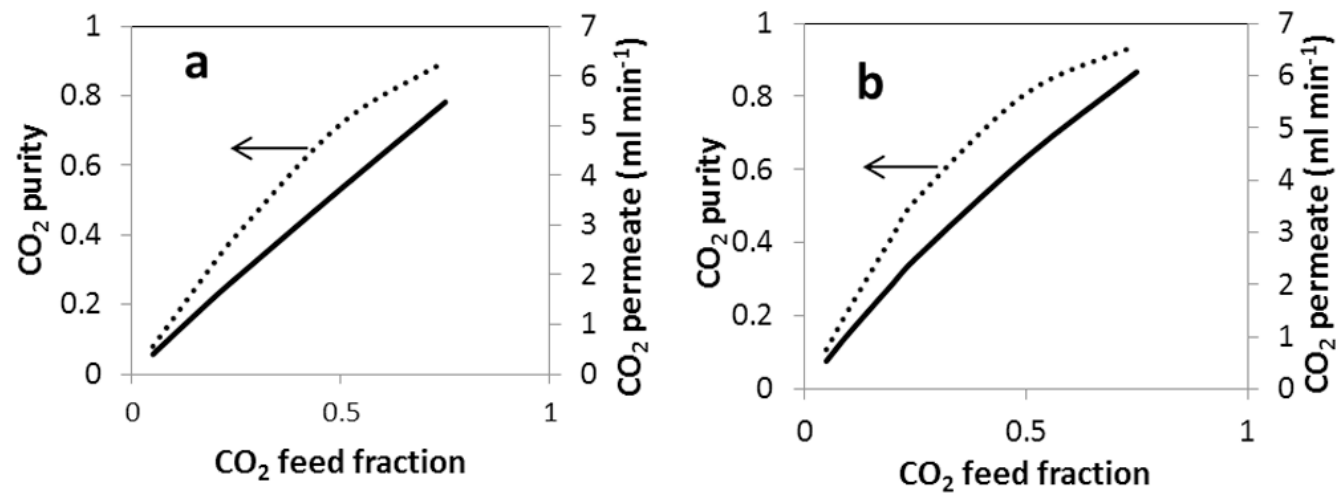

Figure 10: The effect of feed flow rate on separation process at different feed flow rates a) $10 \mathrm{~mL} / \mathrm{min}$ and $\mathbf{b}) 20 \mathrm{~mL} / \mathrm{min}$.

side. It is clear that driving forces increase for both $\mathrm{CO}_{2}$ and $\mathrm{CH}_{4}$ permeation by increasing feed pressure, therefore $\mathrm{CO}_{2}$ fraction remains approximately constant between 4 to 8 barg.

\section{Feed Flow Rate}

The effect of feed flow rate on separation process was investigated with simulation of two feed flow rates of 10 and $20 \mathrm{~mL} / \mathrm{min}$ and results are shown in Figure $10 a$ and $b$, respectively. With comparison of two figures it could be seen that $\mathrm{CO}_{2}$ permeation flow rate increase with feed permeation flow rate due to $\mathrm{CO}_{2}$ inlet increase, furthermore $\mathrm{CO}_{2}$ purity has small change with increasing feed flow rate, which is expected because driving force for both $\mathrm{CO}_{2}$ and $\mathrm{CH}_{4}$ would be increased.

\section{Flow Configuration}

Two different flow configurations were considered: In the first configuration permeate outlet was near the feed and in other case it was considered near retentate outlet. Permeate mole fraction and flow rate in two different flow configurations and two different feed fractions are listed in Table 2. Comparison of two configurations showed that flow configuration has a small effect on permeation flow and fraction, and the results exhibit better separation efficiency in the first configuration.

\section{Membrane Tube Radius}

The effect of membrane tube radius on permeate fraction and flow rate is shown in Figure 11. Figure 11a

Table 2: Effect of Flow Configuration on Permeate Mole Fraction and Flow Rate; with Feed Pressure of 4 Barg

\begin{tabular}{|c|c|c|c|c|}
\hline \multirow{2}{*}{} & \multicolumn{2}{|c|}{$\mathrm{CO}_{2}$ feed fraction: $\mathbf{0 . 2 5}$} & \multicolumn{2}{c|}{$\mathrm{CO}_{2}$ feed fraction: $\mathbf{0 . 7 5}$} \\
\cline { 2 - 5 } & configuration I & configuration II & configuration I & configuration II \\
\hline \hline $\mathrm{CO}_{2}$ purity & 0.65 & 0.58 & 0.96 & 0.95 \\
\hline $\mathrm{CO}_{2}$ permeate $\left(\mathrm{mL} \mathrm{min}{ }^{-1}\right)$ & 2.89 & 2.85 & 6.28 & 6.26 \\
\hline
\end{tabular}



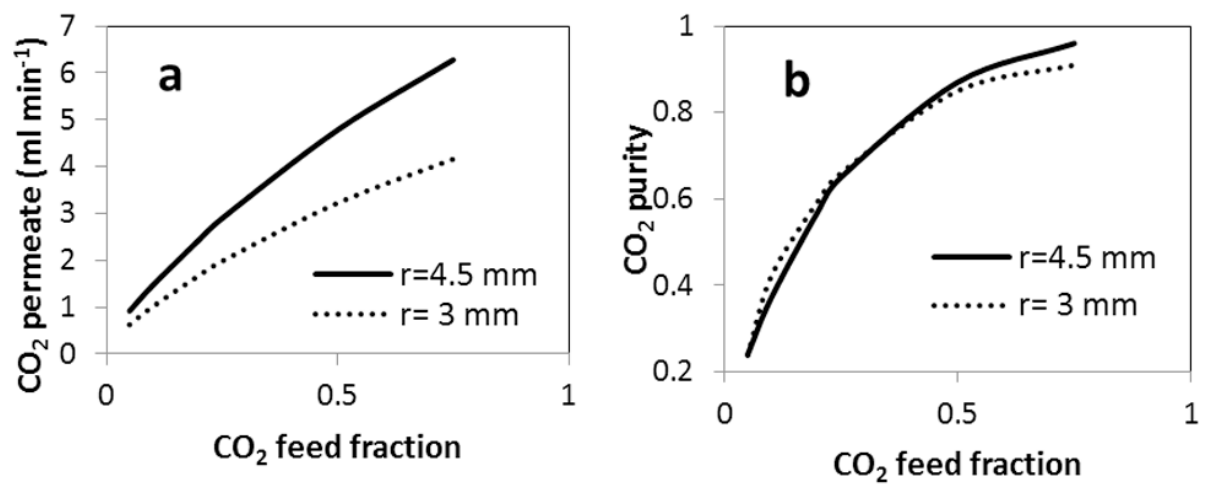

Figure 11: The effect of membrane tube radius on permeate fraction and flow rate.
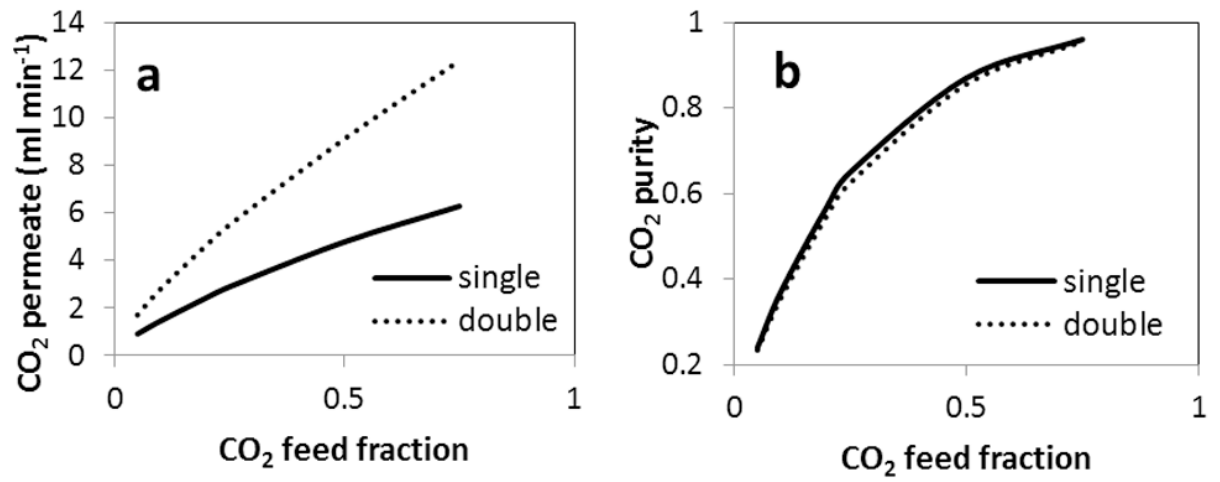

Figure 12: The effect of adding a new membrane in series.

shows $\mathrm{CO}_{2}$ permeate flow rate in two different tube radiuses of 4.5 and $3 \mathrm{~mm}$ while molar flux of feeds remain constant in both cases, due to entrance tube radius is constant in both cases. As could be seen, $\mathrm{CO}_{2}$ permeate flow rate decreases with decreasing the tube radius. The reason is decreasing the internal membrane area therefore less $\mathrm{CO}_{2}$ can become in contact with membrane surface. In addition, Figure 11b illustrates that permeate mole fraction remain constant with change in tube radius, because the driving forces for both gases remain constant.

\section{Membranes in Series}

To show the effect of adding a new membrane in series, some simulation with an additional membrane module were performed and results are shown in Figure 12. It can be seen from Figure 12a that due to connection of a new membrane and increase of membrane area more $\mathrm{CO}_{2}$ permeate was resulted across the membrane, while according to Figure $\mathbf{1 2 b}$ the purity of $\mathrm{CO}_{2}$ was similar for double and single membranes. However, with permeation of more $\mathrm{CO}_{2}$ from the membrane, driving force of $\mathrm{CO}_{2}$ would be decreased, thus a slight decrease in $\mathrm{CO}_{2}$ fraction for double membrane module could be seen.

\section{CONCLUSIONS}

In the present work, a CFD approach was used to simulate movement, diffusion and permeation of $\mathrm{CO}_{2} / \mathrm{CH}_{4}$ gaseous mixture through a tubular SAPO-34 membrane. Results showed good agreement with experimental outlet data for both components as a function of pressure drop along the membrane module. Concentration and velocity maps were obtained and concentration polarization effect was predicted in the feed side. The impact of operating conditions on separation were studied and showed that for enhancement of separation efficiency of $\mathrm{CO}_{2}$ from $\mathrm{CH}_{4}$, feed pressure, feed flow rate and tube radius and number of membrane modules in series should be increased, whereas flow configuration has less significant effect.

\section{ACKNOWLEDGEMENTS}

The authors gratefully acknowledge the financial support of Iran National Science Foundation Nomenclature (INSF). 


\section{APPENDIX: NOMENCLATURE}

$\begin{array}{ll}\text { A } & \text { Area }\left(\mathrm{m}^{2}\right) \\ \text { b } & \begin{array}{l}\text { parameter in Langmuir adsorption isotherm } \\ \left(\mathrm{pa}^{-1}\right)\end{array} \\ \text { D } & \text { Maxwell-Stefan diffusivity }\left(\mathrm{m}^{2} \mathrm{~s}^{-1}\right) \\ \text { D } & \text { Fick diffusivity }\left(\mathrm{m}^{2} \mathrm{~s}^{-1}\right) \\ \mathrm{J} & \text { molar flux }\left(\mathrm{kmol} \mathrm{m}^{-2} \mathrm{~s}^{-1}\right) \\ \mathrm{M} & \text { molecular weight }\left(\mathrm{kg} \mathrm{kmol}^{-1}\right) \\ \mathrm{P} & \text { pressure (pa) } \\ \mathrm{q} & \text { concentration of adsorbed gas }\left(\mathrm{kmol} \mathrm{kg}^{-1}\right) \\ \mathrm{S} & \text { source/dink term }\left(\mathrm{kg} \mathrm{m}^{-3} \mathrm{~s}^{-1}\right) \\ \mathrm{U} & \text { velocity vector }\left(\mathrm{m} \mathrm{s}^{-1}\right) \\ \mathrm{V} & \left.\text { volume (m }{ }^{3}\right) \\ \mathrm{Y} & \text { mass fraction }(-)\end{array}$

\section{Greek Symbols}

$\delta \quad$ membrane thickness (m)

$\theta \quad$ coverage fraction (-)

$\rho \quad$ density $\left(\mathrm{kg} \mathrm{m}^{-3}\right)$

T $\quad$ stress tensor (pa)

\section{Subscripts}

$\begin{array}{ll}c & \text { computational cell } \\ \text { feed } & \text { feed side } \\ i & \text { generic species } \\ j & \text { generic species } \\ \text { perm } & \text { permeation side } \\ \text { sat } & \text { saturation } \\ z & \text { zeolite film }\end{array}$

\section{REFERENCES}

[1] Baker RW. Future Directions of Membrane Gas Separation Technology. Ind Eng Chem Res 2002; 41(6): 1393-411. http://dx.doi.org/10.1021/ie0108088
[2] Rufford TE, Smart S, Watson GCY, Graham BF, Boxall J, Diniz da Costa JC, et al. The removal of CO2 and N2 from natural gas: A review of conventional and emerging process technologies. J Pet Sci Eng 2012; 94-95: 123-54.

http://dx.doi.org/10.1016/j.petrol.2012.06.016

[3] Sridhar S, Smitha B, Aminabhavi TM. Separation of carbon dioxide from natural gas mixtures through polymeric membranes-A Review. Sep Purif Rev 2007; 36(2): 113-74. http://dx.doi.org/10.1080/15422110601165967

[4] Hong M, Li S, Falconer JL, Noble RD. Hydrogen purification using a SAPO-34 membrane. J Memb Sci 2008; 307(2): 27783.

http://dx.doi.org/10.1016/j.memsci.2007.09.031

[5] Krishna R, van Baten JM. Segregation effects in adsorption of CO2-containing mixtures and their consequences for separation selectivities in cage-type zeolites. Sep Purif Technol 2008; 61(3): 414-23. http://dx.doi.org/10.1016/j.seppur.2007.12.003

[6] Ghidossi R, Veyret D, Moulin P. Computational fluid dynamics applied to membranes: State of the art and opportunities. Chem Eng Process 2006; 45(6): 437-54. http://dx.doi.org/10.1016/j.cep.2005.11.002

[7] Fimbres-Weins GA, Wiley DE. Review of 3D CFD modeling of flow and mass transfer in narrow spacer-filled channels in membrane modules. Chem Eng Process 2010; 49(7): 75981.

\section{http://dx.doi.org/10.1016/j.cep.2010.01.007}

[8] Koukou MK, Papayannakos N, Markatos NC, Bracht M, Van Veen HM, Roskam A. Performance of ceramic membranes at elevated pressure and temperature: effect of non-ideal flow conditions in a pilot scale membrane separator. J Memb Sci. 1999; 155(2): 241-59.

http://dx.doi.org/10.1016/S0376-7388(98)00315-9

[9] Takaba H, Nakao Si. Computational fluid dynamics study on concentration polarization in $\mathrm{H} 2 / \mathrm{CO}$ separation membranes. J Memb Sci 2005; 249(1-2): 83-8. http://dx.doi.org/10.1016/j.memsci.2004.09.038

[10] Abdel-jawad MM, Gopalakrishnan S, Duke MC, Macrossan MN, Schneider PS, Diniz da Costa JC. Flowfields on feed and permeate sides of tubular molecular sieving silica (MSS) membranes. J Memb Sci 2007; 299(1-2): 229-35. http://dx.doi.org/10.1016/j.memsci.2007.04.046

[11] Kawachale N, Kumar A, Kirpalani DM. Numerical Investigation of Hydrocarbon Enrichment of Process Gas Mixtures by Permeation through Polymeric Membranes. Chem Eng Technol 2008; 31(1): 58-65. http://dx.doi.org/10.1002/ceat.200700263

[12] Coroneo M, Montante G, Catalano J, Paglianti A. Modelling the effect of operating conditions on hydrodynamics and mass transfer in a $\mathrm{Pd}-\mathrm{Ag}$ membrane module for $\mathrm{H} 2$ purification. J Memb Sci 2009; 343(1-2): 34-41. http://dx.doi.org/10.1016/j.memsci.2009.07.008

[13] Coroneo M, Montante G, Giacinti Baschetti M, Paglianti A. CFD modelling of inorganic membrane modules for gas mixture separation. Chem Eng Sci 2009; 64(5): 1085-94. http://dx.doi.org/10.1016/j.ces.2008.10.065

[14] Ji G, Wang G, Hooman K, Bhatia S, Diniz da Costa JC. Simulation of binary gas separation through multi-tube molecular sieving membranes at high temperatures. Chem Eng J 2013; 218: 394-404. http://dx.doi.org/10.1016/j.cej.2012.12.063

[15] Ji G, Wang G, Hooman K, Bhatia S, Diniz da Costa JC. The fluid dynamic effect on the driving force for a cobalt oxide silica membrane module at high temperatures. Chem Eng Sci 2014; 111: 142-52.

http://dx.doi.org/10.1016/i.ces.2014.02.006

[16] Li H, Schygulla U, Hoffmann J, Niehoff P, Haas-Santo K, Dittmeyer R. Experimental and modeling study of gas 
transport through composite ceramic membranes. Chem Eng Sci 2014; 108: 94-102.

http://dx.doi.org/10.1016/j.ces.2013.12.030

[17] Jabbari Z, Fatemi S, Davoodpour M. Improvement of SAPO34 fine layer formation on ceramic and steel supports by applying uniform-size synthesized seed particles. Asia-Pac J Chem Eng 2013; 8(2): 301-10.

http://dx.doi.org/10.1002/apj.1682

[18] Jareman F, Hedlund J, Creaser D, Sterte J. Modelling of single gas permeation in real MFI membranes. J Memb Sci 2004; 236(1-2): 81-9.

http://dx.doi.org/10.1016/j.memsci.2004.01.028

[19] Nagy E. Basic Equations of the Mass Transport through a Membrane Layer. First ed. Oxford: Elsevier; 2012. 330 p.
[20] Wirawan SK, Creaser D, Lindmark J, Hedlund J, Bendiyasa IM, Sediawan WB. H2/CO2 permeation through a silicalite-1 composite membrane. J Memb Sci 2011; 375(1-2): 313-22. http://dx.doi.org/10.1016/j.memsci.2011.03.061

[21] Martinek JG, Gardner TQ, Noble RD, Falconer JL. Modeling Transient Permeation of Binary Mixtures through Zeolite Membranes. Ind Eng Chem Res 2006; 45(17): 6032-43. http://dx.doi.org/10.1021/ie060166u

[22] Ansys Fluent User's Guide, Release 13.0: Ansys Inc.; 2010.

[23] Li S, Falconer JL, Noble RD, Krishna R. Modeling Permeation of $\mathrm{CO} 2 / \mathrm{CH} 4, \mathrm{CO} 2 / \mathrm{N} 2$, and $\mathrm{N} 2 / \mathrm{CH} 4$ Mixtures Across SAPO-34 Membrane with the Maxwell-Stefan Equations. Ind Eng Chem Res 2007; 46(12): 3904-11. http://dx.doi.org/10.1021/ie0610703 